\title{
GERMINAÇÃO DE SEMENTES REVESTIDAS E NÃO REVESTIDAS DE Panicum maximum cv. TANZÂNIA EM CONDIÇÕES DE DEFICIÊNCIA HÍDRICA
}

\author{
Fernando Donha Bianchi ${ }^{1}$; Luciana de Oliveira Derré ${ }^{2}$ Fabiana Lima Abrantes ${ }^{3}$; Ceci Castilho Custódio ${ }^{3}$ \\ ${ }^{1}$ Engenheiro Agrônomo. ${ }^{2}$ Faculdade Centro Mato-Grossense - FACEM, Curso de Agronomia, Sorriso, MT. ${ }^{3}$ Universidade \\ do Oeste Paulista - UNOESTE, Programa de Pós Graduação em Agronomia, Presidente Prudente, SP. E-mail: \\ ceci@unoeste.br
}

\section{RESUMO}

O objetivo desse estudo foi avaliar a resposta de sementes revestidas e não revestidas em duas condições hídricas, quanto à germinação e o desempenho inicial de plântulas. $O$ experimento foi realizado no Laboratório de Análise de Sementes da Universidade do Oeste Paulista (UNOESTE), utilizando sementes comerciais revestidas e não revestidas de Panicum maximum Jacp. cv. Tanzânia. Utilizou-se o delineamento inteiramente casualizado, em esquema fatorial $2 \times 2$, com quatro repetições, sendo 2 tipos de sementes (revestidas e não revestidas) e dois potenciais hídricos (0 e -0,6 MPa). Avaliou-se: germinação de sementes, comprimento da parte aérea e raiz e suas massas de matéria seca. A diferença de potencial hídrico reduz a germinação independente do tipo de sementes. A germinação das sementes revestidas foi superior às sementes não revestidas. Em condição de restrição hídrica as sementes revestidas proporcionam plântulas com maior crescimento de parte aérea. Em condição de disponibilidade de água proporcionaram menor crescimento de raiz.

Palavras-chave: deficiência hídrica; forrageira; gramínea; manitol; revestimento de sementes.

\section{GERMINATION OF COATED AND UNCOATED SEEDS OF PANICUM MAXIMUM CV. TANZANIA IN WATER STRESS CONDITIONS}

\begin{abstract}
The aim of this study was to evaluate the coated seeds response and uncoated two water conditions for germination and early seedling performance. The experiment was conducted the Seed Analysis Laboratory of the Universidade do Oeste Paulista (UNOESTE) using coated and uncoated commercial seed of Panicum maximum Jacp. cv. Tanzania. We used a completely randomized design in a factorial $2 \times 2$, with four replications, with 2 types of seeds (coated and uncoated) and two water potential ( 0 and $-0.6 \mathrm{MPa}$ ). Were evaluated: seed germination, shoot length and root and its mass of dry matter. The difference in water potential reduces germination independent of the type of seed. Germination of the pelleted seed was superior to uncoated seeds. In water stress condition the coated seeds provide seedlings with greater shoot growth. In conditions of water availability provided lower root growth.
\end{abstract}

Keywords: watter stress; forage; grass; mannitol; seed coating.

\section{INTRODUÇÃO}

Nos últimos anos a produção de sementes de forrageiras tropicais no Brasil tem crescido muito, sendo as cultivares da espécie Panicum maximum as principais cultivadas no Brasil, destacando-se a Panicum maximum Jacq. cv. Tanzânia, devido sua alta capacidade de produção de matéria seca, por suas excelentes características agronômicas (GOMES et al., 2011).

Para atender a demanda por tecnologias que melhorem a rentabilidade da pecuária brasileira, o revestimento de sementes, através da incrustação, se tornou uma solução tecnológica na busca por melhores resultados em termos de produtividade, melhorando a pureza física e facilitando a semeadura devido ao seu aumento de tamanho (BRITES et al., 2011).

Além de boa tecnologia são necessárias condições ambientais favoráveis para o início da germinação e desenvolvimento da planta, pois a primeira etapa da germinação ocorre a partir da embebição das sementes, ou seja, da absorção de água, reidratando os tecidos e desencadeando atividades metabólicas, necessárias para retomada 
do crescimento do eixo embrionário e protrusão da raiz primária (MARCOS FILHO, 2005). Assim, quando expostas em potenciais hídricos muito negativos, na fase inicial da embebição, pode ocorrer redução drástica da absorção de água pelas sementes, podendo inviabilizar a sequência de eventos do processo germinativo (BANSAL et al., 1980).

Assim, o objetivo desse estudo foi avaliar a resposta de sementes revestidas e não revestidas de capim Tanzânia em duas condições hídricas, quanto à germinação e o desempenho inicial de plântulas.

\section{METODOLOGIA}

O experimento foi realizado no Laboratório de Análise de Sementes da Universidade do Oeste Paulista (UNOESTE), localizado em Presidente Prudente (SP) em 2013. Foram utilizadas sementes comerciais revestidas (Advanced ${ }^{\mathrm{TM}}$ ) utilizando polímero, grafite, fungicida e inseticida e não revestidas (nuas), de Panicum maximum Jacp. cv. Tanzânia, originárias de mesmo lote colhido no campo.

Para a caracterização do lote foi avaliada a viabilidade das sementes através do teste de tretazólio (TZ) nas sementes revestidas e não revestidas, sendo avaliadas quatro repetições de 25 sementes para cada lote, seguindo a metodologia proposta por Custódio et al. (2012). As sementes foram consideradas vivas e não vivas de acordo com a localização e intensidade da coloração de suas partes (BRASIL, 2009), sendo os resultados expressos em porcentagem.

Para a determinação do teor de água das sementes, foi utilizado o método de estufa $105^{\circ} \pm$ $3^{\circ} \mathrm{C}$ por 24 horas, utilizando quatro repetições para cada lote, com aproximadamente $5,0 \mathrm{~g}$ de semente, e os resultados foram expressos em porcentagem de acordo com as Regras para Análise de Sementes - RAS (BRASIL, 2009).

A massa de 1000 sementes foi obtida a partir de oito repetições de 100 sementes para cada lote (sementes revestidas e não revestidas), as quais foram pesadas em balança de precisão $(0,0001 \mathrm{~g})$, conforme as RAS (BRASIL, 2009), expressando-se os valores médios com e sem correção da umidade para $13 \%$. Com os valores corrigidos foi calculada a razão de revestimento dividindo-se a massa das sementes revestidas pela massa das não revestidas.

Utilizou-se o delineamento inteiramente casualizado, em esquema fatorial $2 \times 2$, com quatro repetições, sendo 2 tipos de sementes (revestidas e não revestidas) e dois potenciais hídricos (0 e -0,6 MPa) obtido a partir de solução de manitol na concentração de 0 e 44,58 $\mathrm{g} \mathrm{L}^{-1}$, respectivamente, calculados pela fórmula de Van't Hoff (TAIZ; ZEIGER, 2014).

Os resultados foram comparados pelo teste $F(p \leq 0,10)$, utilizando para a análise dos dados o programa estatístico SISVAR (FERREIRA, 2011).

O teste de germinação foi conduzido com quatro repetições de 100 sementes por tratamento, com as sementes distribuídas de maneira equidistante em caixas plásticas (gerbox), sobre duas folhas de papel para germinação, umedecidas com as soluções na quantidade correspondendo a 2,5 vezes a massa do papel não hidratado. As caixas plásticas foram mantidas em câmara de germinação com controle de fotoperíodo, à temperatura alternada de $15-35$ 으, por 16 horas no escuro, para a menor temperatura, e oito horas sob luz, para a maior. As contagens foram realizadas aos 7, 14 e 21 dias, considerando os critérios estabelecidos pelas RAS para plântulas normais (BRASIL, 2009), sendo acrescentado $3 \mathrm{ml}$ de água pura, para a reposição de umidade.

Índice de velocidade de germinação (IVG): foi conduzido em conjunto com o teste de germinação, dividindo o número de sementes germinadas pelo número de dias decorridos entre a semeadura e a contagem (MAGUIRE et al., 1962).

Para avaliar o comprimento da parte aérea e raiz, bem como a massa de matéria seca dessas partes seguiu-se a metodologia proposta por Nakagawa (1994), e utilizou-se quatro repetições de 20 sementes distribuídas em toalhas de papel para germinação, umedecidas com as soluções na quantidade correspondente a 2,5 vezes a massa do papel não hidratado. As sementes foram distribuídas de maneira equidistante no centro das folhas de papel (duas base e uma cobertura), formando uma única linha, enroladas e levadas à câmara de germinação com as mesmas condições descritas para o teste de germinação. Após 15 dias da instalação dos testes as plântulas foram seccionadas e medidas com régua milimétrica a parte aérea e a raiz. Posteriormente, estas partes foram acondicionadas separadamente em sacos de papel fino devidamente identificados e levados para estufa de circulação forçada de ar a $60^{\circ} \mathrm{C}$ por 24 horas. Após este período, os materiais foram colocados para esfriar em dessecador e pesados em balança analítica de precisão. 


\section{RESULTADOS}

A viabilidade das sementes, avaliada pelo TZ das sementes revestidas foram 3 pontos percentuais a mais que as não revestidas (Tabela 1), demonstrando que o tratamento de revestir sementes não afetou a viabilidade das sementes. A determinação de umidade indicou que 0 revestimento, por ser constituído de material que não retém água (principalmente grafite), ao praticamente dobrar a massa das sementes, como observado na razão de revestimento, reduziu proporcionalmente o teor de água das sementes revestidas em comparação com não revestidas.

Tabela 1. Valores médios obtidos para viabilidade pelo teste de tetrazólio (TZ), teor de água nas sementes (U) e massa de mil sementes (MMS) para sementes revestidas e não revestidas de Panicum maximum Jacq cv. Tanzânia.

\begin{tabular}{lccccc}
\hline Sementes & TZ (\%) & U (\%) & MMS (g) & MMS (g) & RR \\
\hline Revestida & 83 & 5,4 & 2,43 & 2,64 & \multirow{2}{1}{ Não Revestida } \\
Nân & 80 & 8,0 & 1,29 & 1,36 & \\
\hline
\end{tabular}

${ }^{1}=$ massa de mil sementes com umidade corrigida para $13 \%$, RR=razão de revestimento com valores corrigidos para $13 \%$ (MMS R. MMS NR ${ }^{-1}$ ).

Diante dos dados apresentados na Tabela 2 , pode-se observar que houve interação entre os fatores: potencial hídrico e tipos de sementes (revestidas e não revestidas), para germinação de sementes, comprimento de parte aérea e raiz. Enquanto que para o índice de velocidade de germinação (IVG) o efeito observado foi apenas para potencial hídrico (Tabela 2), e para massa seca de parte aérea e raiz não observou-se diferença significativa entre os tratamentos. As sementes submetidas à deficiência de água simulada pela solução de manitol, responderam diminuindo o IVG e a porcentagem de germinação (Tabela 2).
Observa-se através dos dados de desdobramento da interação potencial hídrico $\mathrm{x}$ tipo de sementes para germinação que quando a germinação ocorreu em água às sementes revestidas proporcionaram maior porcentagem de germinação, sendo $16 \%$ superiores às não revestidas e quando utilizado manitol não houve diferença entre os tipos de sementes (Tabela 3 ).

Tanto para as sementes revestidas como para às não revestidas, de acordo com o aumento da deficiência de água, ocorreu a diminuição da germinação. Porém, as sementes revestidas germinaram cerca de $3 \%$ a menos que as sementes sem revestimento.

Tabela 2. Valores médios obtidos de germinação (G), índice de velocidade de germinação (IVG), comprimento de parte aérea (CPA), comprimento de raiz (CR), massa seca de parte aérea (MSRA) e massa seca de raiz (MSR) em diferentes potenciais hídricos, comparando os tipos de sementes revestidas e não revestidas de Panicum maximum Jacq cv. Tanzânia.

\begin{tabular}{lcccccc}
\hline Tratamento & G & IVG & CPA & CR & MSPA & MSR \\
\hline $\begin{array}{l}\text { Potencial hídrico (A) } \\
\text { Água }\end{array}$ & 61 & $4,87 \mathrm{a}$ & $3,57 \mathrm{a}$ & $4,14 \mathrm{a}$ & 0,0050 & 0,0022 \\
Manitol & 21 & $1,25 \mathrm{~b}$ & $2,35 \mathrm{~b}$ & $3,39 \mathrm{~b}$ & 0,0056 & 0,0026 \\
\hline Tipo de Semente (B) & 44 & 3,00 & 3,01 & 3,59 & 0,0052 & 0,0022 \\
Revestida & 37 & 3,12 & 2,91 & 3,94 & 0,0053 & 0,0026 \\
Não Revestida & $101,99^{* *}$ & $168,20^{* *}$ & $139,86^{* *}$ & $3,94^{*}$ & $0,94^{\text {ns }}$ & $1,23^{\text {ns }}$ \\
& $2,69^{\text {ns }}$ & $0,20^{\text {ns }}$ & $0,93^{\text {ns }}$ & $0,86^{\text {ns }}$ & $0,002^{\text {ns }}$ & $1,08^{\text {ns }}$ \\
\hline Potencial hídrico (A) & $5,75^{*}$ & $1,80^{\text {ns }}$ & $3,73^{*}$ & $11,38^{* *}$ & $0,03^{\text {ns }}$ & $1,74^{\text {ns }}$
\end{tabular}

Médias seguidas de letras distintas, na coluna, para os fatores solução e tipo de semente, diferem entre si estatisticamente, pelo Teste $\mathrm{F}$ a $10 \%$ de probabilidade. $\mathrm{ns},{ }^{* *}$ e * são: não significativo e significativo a $1 \%$ e a $10 \%$ de probabilidade pelo teste $\mathrm{F}$. 
Tabela 3. Desdobramento da interação potencial hídrico $x$ tipo de sementes para germinação de sementes de Panicum maximum Jacq cv. Tanzânia.

\begin{tabular}{lcc}
\hline Potencial hídrico & \multicolumn{3}{c}{ Tipo de Semente } \\
\cline { 2 - 4 } & Revestida & Não Revestida \\
\hline Água & $69 \mathrm{aA}$ & $53 \mathrm{aB}$ \\
Manitol & $19 \mathrm{bA}$ & $22 \mathrm{bA}$ \\
\hline
\end{tabular}

Médias seguidas de letras minúsculas, distintas, na coluna, e maiúsculas, na linha, diferem estatisticamente entre si, pelo teste $\mathrm{F}$ a $10 \%$ de probabilidade.

Em relação aos dados de comprimento da parte aérea e de raiz de plântulas (Tabela 4), houve diferença significativa para a interação potencial hídrico e tipo de semente, sendo que quando as sementes foram expostas a deficiência de água, as sementes revestidas apresentaram parte aérea $0,30 \mathrm{~cm}$ maior do que as plântulas oriundas de sementes sem revestimento. Ao analisar o desenvolvimento de parte aérea na condição de diferentes potenciais hídricos observa-se que independente do tipo de sementes as plântulas que cresceram em restrição hídrica foram inferiores as que se desenvolveram sem restrição de água.

No desdobramento da interação entre potencial hídrico e tipo de sementes para comprimento de raiz, observa-se que as sementes não revestidas proporcionaram plântulas com raiz, em média, 1,63 cm superior à média de raiz de plântulas originada de sementes revestidas, quando crescidas em meio sem restrição hídrica (água). Já para as plântulas desenvolvidas em meio com restrição não houve diferença entre os tipos de sementes. Porém ao analisar o comprimento de raiz das plântulas originadas de sementes revestidas, verifica-se que para as mantidas em meio sem restrição (água) não houve diferença significativa, mas para as sementes não revestidas a raiz das plântulas mantidas em meio com restrição hídrica foi inferior às mantidas em água (Tabela 4).

Tabela 4. Desdobramento da interação potencial hídrico x tipo de sementes para comprimento de parte aérea $(\mathrm{cm})$ e de raiz de plântulas de Panicum maximum Jacq cv. Tanzânia.

Potencial hídrico
Comprimento de parte aérea
Água
Manitol
Comprimento de raiz (cm)
Água
Manitol
Médias seguidas de letras minúsculas, distintas, na coluna,
teste F a 10\% de probabilidade.
DISCussão
A viabilidade de sementes revestidas foi
apenas $3 \%$ superior as não revestidas, mostrando
que o revestimento não afetou a viabilidade das
sementes, discordando de Brites et al. (2011) que
constatou um maior número de sementes mortas
no teste de germinação para as sementes
revestidas, quando avaliou a germinação de
semente comum, escarificada e revestida de
diferentes espécies de forrageiras tropicais.

Tipo de Semente

Revestida Não Revestida

$3,52 \mathrm{aA} \quad 3,62 \mathrm{aA}$

$2,50 \mathrm{bA} \quad 2,20 \mathrm{bB}$

$3,32 \mathrm{aB} \quad 4,95 \mathrm{aA}$

$3,85 \mathrm{aA} \quad 2,92 \mathrm{bA}$ 
revestidas obtiveram $16 \%$ a mais que às não revestidas provavelmente em consequência da proteção fornecida principalmente pelo fungicida contido no revestimento, pois, durante a germinação enquanto a semente embebe ocorre a liberação de exsudatos ricos em açucares que propiciam o crescimento de microrganismos cujo fungicida pode conter. Esses resultados permitem discordar de Câmara e Seraphin (2002), que constataram inibição na germinação de sementes de Brachiaria brizantha após revestimento, atribuindo à restrição da entrada e saída de água, além do bloqueio das trocas gasosas. As sementes colocadas para germinar em solução de água destilada, germinaram $40 \%$ a mais que as em solução de manitol. Resultados semelhantes foram encontrados por Custódio et al. (2011), trabalhando com sementes intactas e peliculizadas de Brachiaria Brizantha (Hoschst, ex A. Rich.) Staf, em diferentes potenciais osmóticos simulados por manitol, onde observaram a redução da germinação em sementes exposta ao estresse hídrico.

À medida que a quantidade de água decresce, ocorre a diminuição do potencial hídrico do substrato em que se encontrada a semente. Com isso a absorção de água, pela semente, é dificultada, e dependendo do valor do potencial hídrico pode não ocorrer absorção (TAIZ; ZEIGER, 2014). Tal fato, explica a diminuição do índice de velocidade de germinação e a germinação, pois o potencial hídrico gerado pelo manitol no substrato foi menor, fazendo com que esta não conseguisse absorver água necessária para a germinação.

Porém, as sementes revestidas germinaram cerca de $3 \%$ menos que as sementes sem revestimento, pois o polímero possui a capacidade de restringir a absorção de água em condições de deficiência hídrica, controlando a hidratação (EVANGELISTA et al., 2007; SAMPAIO; SAMPAIO, 2009). De acordo com Custódio et al. (2011), o revestimento de sementes, evita que a sementes absorva água de forma acelerada, devido à capacidade do polímero em reduzir a embebição.

O comprimento de parte aérea e de raiz de sementes revestidas e não revestidas foi menor nas plântulas crescidas em condição de restrição hídrica. E em condições de estresse hídrico o primeiro efeito mensurável é uma diminuição no crescimento causada pela redução da expansão celular que necessita de potencial de turgor adequado. A capacidade da planta de obter água está relacionada à sua capacidade de desenvolver um extenso sistema radicular. As raízes das plantas podem crescer continuamente ao longo do tempo, no entanto, depende da disponibilidade de água (TAIZ; ZEIGER, 2014).

A massa seca de parte aérea e raiz não foi influenciada pelo revestimento da semente e nem pela diferença de potencial hídrico, diferente do observado por Christovam et al. (2015) que verificaram redução na massa seca de plântulas mediante aumento na restrição de água para $U$. brizantha cultivares MG4, MG5, Marandu e BRSPiatã.

\section{CONCLUSÃO}

As sementes revestidas, quando em condições de disponibilidade de água, apresentaram maior porcentagem de germinação, em relação às não revestidas.

$O$ revestimento de sementes não interfere no índice de velocidade de germinação, massa seca de parte aérea e raiz.

A restrição hídrica diminui a germinação, crescimento de parte aérea e de raiz.

Em condição de restrição hídrica as sementes revestidas proporcionam plântulas com maior crescimento de parte aérea. Em condição de disponibilidade água proporcionaram menor crescimento de raiz.

\section{REFERÊNCIAS}

BANSAL, R.P.; BHATI, P.R.; SEN, D.N. Differential specificity in water inhibition of Indian arid zone. Biologia Plantarum, v.22, p.327-331, 1980.

BRASIL. Ministério da Agricultura. Regras para análises de sementes. Brasília: SNAD/DNAV/CLAV, 2009.

BRITES, F. H. R.; SILVA JUNIOR, C. A.; TORRES F. E. Germinação de semente comum, escarificada e revestida de diferentes espécies forrageiras tropicais. Bioscience Journal, v.27, n.4, p.629-634, $2011 . \quad$ Disponível em: <http://www.seer.ufu.br/index.php/biosciencejou rnal/article/view/11267/7754>

CAMARA, H.H.L.L; SERAPHIN, S.E. Germinação de sementes de Urochloa brizantha cv Marandu sob diferentes períodos de armazenamento e tratamento hormonal. Pesquisa Agropecuária Tropical, v.32, n.1, p.21-28, 2002. Diponível em: $<$ http://www.revistas.ufg.br/index.php/pat/article /view/2436>

CHRISTOVAM, M.C.; SILVA, T.L.; YAMAMOTO, C.J.T.; MOREIRA, A.L.L.; CUSTÓDIO, C.C.; PACHECO, A.C.; ABRANTES, F.L. Germinação e desenvolvimento inicial de plântulas de cultivares de Urochloa brizantha em condições de estresse hídrico. Informativo Abrates, v.25, n.1, p.43-49, 
$2015 . \quad$ Disponível em: <http://www.abrates.org.br/informativo/artigospublicados/1267-informativo-abrates-volume-25numero-1-2015>

CUSTÓDIO, C. C.; AMBIEL, A. C.; RODRIGUES, D. Z.; AGOSTINI, E. A. T.; FACTUR, V. D.; PAVANELLI L.E. Peliculização de sementes intactas e escarificadas de Brachiaria brizantha (Hochst. ex A. Rich.) Stapf 1. Pesquisa Agropecuária Tropical, v.41, n.3, p.314-321, 2011. https://doi.org/10.5216/pat.v41i3.9146.

CUSTÓDIO, C.C.; DAMASCENO, R.L.; MACHADO NETO, N.B. Imagens digitalizadas na interpretação do teste de tetrazólio em sementes de Brachiaria brizantha. Revista Brasileira de Sementes, v.34, n.2, p.334-341, 2012. http://dx.doi.org/10.1590/S0101-

31222012000200020

EVANGELISTA, J. R. E.; OLIVEIRA, J. A.; BOTELHO F. J. E.; OLIVEIRA, R. M. E.; PEREIRA, C. E. Desempenho de sementes de soja peliculizadas em solo com diferentes teores de água. Ciência e Agrotecnologia, v.31, n.4, p.994-999, 2007. http://dx.doi.org/10.1590/S1413-

70542007000400008

FERREIRA, D. F. Sisvar: um sistema computacional de análise estatística. Ciência e Agrotecnologia, v.35, n.6, p.1039-1042, 2011. http://dx.doi.org/10.1590/S1413-

70542011000600001

GOMES, R. A.; LEMPP, B.; JANK L.; CARPEJANI, G. C.; MORAIS, M. G. Características anatômicas e morfofisiológicas de lâminas foliares de genótipos de Panicum maximum. Revista Pesquisa Agropecuária Brasileira, v.46, n.2, p.205-211, 2011.

http://seer.sct.embrapa.br/index.php/pab/article/ view/2469/6239

MAGUIRE, J. D. Speeds of germination-aid selection and evaluation or seedling emergence and vigor. Crop Science, v.2, p.176-177, 1962.

MARCOS FILHO, J. F. Fisiologia de sementes de plantas cultivadas. Piracicaba: FEALQ, 2005. 495p.

NAKAGAWA, J. Teste de vigor baseados na avaliação das plântulas. In: VIEIRA, R. D.; CARVALHO, N. M. (Ed.). Testes de vigor em sementes. Jaboticabal: FUNEP, 1994. p. 49-85.

SAMPAIO, T. G.; SAMPAIO, N. V. Recobrimento de sementes de hortaliças. In: NASCIMENTO, W. M. Tecnologia de sementes de hortaliças. Brasília: Embrapa Hortaliças, 2009. p. 275-306.

TAIZ, L.; ZEIGER, E. Fisiologia vegetal. 5 ed. Artmed: Porto Alegre, 2014. 954.
Recebido para publicação em 01/08/2016 Revisado em 19/08/2016

Aceito em 26/08/2016 